\title{
Detecting Factors Effective in Knowledge Sharing Model Among Educational Staff
}

\section{Detección de factores efectivos en el modelo de intercambio de conocimientos entre el personal educativo}

\author{
Farahmand Zebardast \\ Department of Educational Sciences, Khorramabad Branch, Islamic Azad University, \\ Khorramabad, Iran. \\ ORCID: https://orcid.org/0000-0002-7244-0609 \\ Hossein Mehrdad* \\ Department of Educational Sciences, Khorramabad Branch, Islamic Azad University, \\ Khorramabad, Iran. \\ ORCID: https://orcid.org/0000-0001-8354-6233

\section{Razieh Jalili} \\ Department of Educational Sciences, khorramabad Brannch, Islamic Azad University, \\ Khorramabad, Iran. \\ ORCID: https://orcid.org/0000-0003-4640-1507
}

Received 01-12-20 Revised 01-25-20 Accepted 04-13-20 On line 06-29-20

*Correspondence

Email: sinamhr@gmail.com
Cite as:

Zebardast, F., Mehrdad, H., \& Jalili, R. (2020). Detecting Factors Effective in Knowledge Sharing Model Among Educational StaffPropósitos y Representaciones, 8 (SPE2), e805. Doi: http://dx.doi.org/10.20511/pyr2020.v8nSPE2.805 


\section{Summary}

One of the effective organs in implementing economic, social and cultural development policies in each country is the Ministry of Education, which trains specialized and experienced manpower as the basis for the comprehensive development of countries, production of knowledge and research knowledge, and the provision of specialized services by universities and higher education centers. Accordingly, it facilitates sharing knowledge and identifying factors affecting it in the education organization, especially among employees who are the most important elements in any organization. Because it can create an atmosphere full of trust and interaction, the employees can share their knowledge and experiences with each other; hence, it can be an important strength for the education organization as well as society. In this regard, the present study aimed to identify the factors affecting the knowledge sharing model in individual, organizational, environmental, and extra-environmental dimensions among educational staff. The study revealed that the main individual dimension includes enjoyment of knowledge sharing, organizational commitment, specific organizational knowledge, trust, motivation, value of knowledge, and individual and group interactions. Organizational dimension also encompasses organizational culture, documentation development, in-house planning and organizational rewards. The environmental dimension includes technical knowledge, information technology context, knowledge memory upgrading, and economic and social factors. The trans-environmental dimension consists of political and legal factors and international interactions. This descriptive-analytical research used a library technique.

Keywords: Design and test, Model, Knowledge sharing, Knowledge sharing model, Educational staff.

\section{Resumen}

Uno de los órganos efectivos en la implementación de las políticas de desarrollo económico, social y cultural en cada país es el Ministerio de Educación, que capacita mano de obra especializada y experimentada como base para el desarrollo integral de los países, la producción de conocimiento y conocimientos de investigación y la provisión de servicios especializados de universidades y centros de educación superior. En consecuencia, facilita compartir conocimientos e identificar los factores que lo afectan en la organización educativa, especialmente entre los empleados que son los elementos más importantes en cualquier organización. Debido a que puede crear una atmósfera llena de confianza e interacción, los empleados pueden compartir sus conocimientos y experiencias entre ellos; por tanto, puede ser una fortaleza importante para la organización educativa y para la sociedad. En este sentido, el presente estudio tuvo como objetivo identificar los factores que afectan el modelo de intercambio de conocimiento en las dimensiones individual, organizacional, ambiental y extraambiental entre el personal educativo. El estudio reveló que la principal dimensión individual incluye el disfrute del intercambio de conocimientos, el compromiso organizacional, el conocimiento organizacional específico, la confianza, la motivación, el valor del conocimiento y las interacciones individuales y grupales. La dimensión organizativa también abarca la cultura organizativa, el desarrollo de documentación, la planificación interna y las recompensas organizativas. La dimensión ambiental incluye conocimientos técnicos, contexto de tecnología de la información, actualización de la memoria de conocimientos y factores económicos y sociales. La dimensión transambiental consiste en factores políticos y legales e interacciones internacionales. Esta investigación descriptivoanalítica utilizó una técnica de biblioteca.

Palabras clave: Diseño y prueba, modelo, intercambio de conocimientos, modelo de intercambio de conocimientos, personal educativo. 


\section{Introduction}

One of the main challenges for managers in organizations is getting people to share what they know. Knowledge sharing in organizations leads to faster individual and organizational learning, increases creativity, and leads to improved individual and organizational performance. It is on this basis that organizations strengthen knowledge sharing and encourage their employees to do so. One of the issues in implementing knowledge management in organizations is the issue of knowledge sharing within the organization and between different organizations. On the other hand, the first and perhaps the most difficult step in designing a knowledge management plan is to develop a strategy and model for knowledge sharing in organizations. The education organization of each country is one of the effective factors in implementing its economic, social and cultural development policies. Training specialized and experienced manpower as the basis for comprehensive development of countries, production of knowledge, research knowledge and provision of specialized services by universities. And higher education centers. Therefore, sharing knowledge and identifying the factors affecting it in the education organization and especially among employees who are the most important elements in any organization is important because it can create an atmosphere full of trust and interaction between them so that Be able to share their knowledge and experiences with each other, which in turn can be an important strength for the education organization as well as the community.

\section{Statement of the Problem}

Organizations consider knowledge as a strategic resource to maintain their dynamism and survival in the face of environmental change and vast advances, as this important asset can make organizations more resilient than they can be in today's challenging environment. Achieve their strategic goals. This valuable asset, i.e. knowledge alone, cannot be a competitive advantage for the organization; however, it must be managed to make optimal use of it. Knowledge management is an issue that has attracted the attention of organizations in recent decades. Through knowledge management, organizations can manage the knowledge of their employees and apply it to their goals.

One of the important strategies for establishing and applying knowledge management in organizations is the knowledge sharing process. Knowledge sharing is the process by which individuals mutually transfer their knowledge and experiences to each other. Knowledge sharing is highly valuable for organizations and prevents the outflow of knowledge storage from the organization (Namvar et al., 2018). In the present age, when knowledge has become a strategic resource for organizations and societies, the need to develop and master the methods of creating, sharing, and applying such knowledge has become vital. Successful organizations, meanwhile, are those that recognize the importance of what they know and strive to gain knowledge about what they do not know. Organizations have a wealth of information about the business environment, products, services, processes, technologies, consumers, customers, sponsors, and competitors that they can use to grow their organization; however, there is still information in the minds of employees. It is not easily accessible and if a mechanism is not found to obtain this information, with the departure of employees from the organization, their knowledge will be removed from the organization with them (Mehdian Rad et al., 2018). Even today, in various organizations, managers are eager to create knowledge management systems within organizations to benefit from its useful results. One of the most important and common processes in various structures introduced for knowledge management is knowledge sharing and motivating individuals to share their knowledge in organizations is one of the most important priorities of knowledge management practitioners in the world (Khayat Moghadam et al., 2017). In the concept of knowledge sharing, the behavior of employees and what is in their minds is considered and is considered as an effective factor in the successful implementation of knowledge management. The concept of knowledge sharing is based on the sharing of values, existing 
information, and systematic expert attitudes that provide a framework for evaluating and benefiting from new experiences and information. And provides individuals with the opportunity to be informed of their existing knowledge and educational needs (Akhavan \& Hosseini, 2016).

\section{Definition of Concepts}

(Davenport \& Prosak, 1998) have defined knowledge sharing as a process that involves the exchange of knowledge between individuals and groups. Knowledge Sharing is described by (Ali Purdarvishi, 2012) as saying that when a person shares his knowledge, it means that he is guiding another person using his knowledge, insights and thoughts to help him. To see their situation better. In addition, the person sharing their knowledge ideally should be aware of the purpose of the shared knowledge and its application, as well as the information needs and gaps of the knowledge recipient. According to (Kashani \& Nikokar Hani, 2014), knowledge sharing involves the exchange of valuable information and experiences between two or more persons in their daily interactions. In this regard, knowledge sharing is associated with interactions among different employees. (Akhavan et al., 2017) believe that knowledge sharing is a process through which one unit (individual, group, department, department, etc.) is influenced by the experiences of another unit. (Mehdian Rad et al., 2018), state that knowledge sharing is a process in which individuals voluntarily share their overt and covert knowledge with other employees in various ways such as written, spoken, expressed, and formal and informal dissemination. Knowledge sharing, like organizational learning, strongly emphasizes interactions among individuals in an organization. Knowledge sharing is the process by which individuals are able to transform their knowledge in a way that is understood, absorbed and used by others. Knowledge sharing helps individuals to learn from each other and thus help the basic knowledge of the organization.

Accordingly, knowledge is a valuable and strategic resource and also as an important asset, without which providing quality products and services in the absence of proper management is difficult and sometimes impossible. Hence, knowledge along with labor resources, land, and capital has been introduced as a new asset. In such a structure, knowledge is the main axis, in which the members of the organization have become individuals who transfer their knowledge and experiences to each other and benefit from it. The Education Organization, as the custodian of knowledge production and sharing, has a key role to play in disseminating the culture and structure of knowledge sharing in the public and private sectors. Improving the quality and quantity of knowledge sharing in this institution and spreading this culture among professors, students and staff of this organization will lead to improving the performance of knowledge sharing at other levels and sections of society. In fact, the education organization reflects the progress of the country's knowledge-based progress and its ability to manage human capital and their growth and excellence. The education organization is an institution having extensive connections with all areas and levels at a society and links most organizations and social institutions. Accordingly, knowledge sharing in the education organization is a key element of success in achieving the goals of the organization plays an important role. One of the key and important factors in increasing the efficiency of any organization is the ability of that organization to transfer and share knowledge, and individuals help the organization to achieve a competitive advantage by using and transferring knowledge effectively. Without knowledge sharing, organizations will gradually lose their competitiveness. Knowledge sharing plays a vital role in the success of the organization and the dynamism of organizations in this direction is in learning knowledge and gaining experience of employees and applying these experiences and skills in performing organizational tasks and roles (Sinaei et al., 2017).

Knowledge sharing is a process by which individuals exchange information, transform individual knowledge into organizational knowledge, and potentially through this process the opportunity to learn new experiences and the opportunity to practice and implement experiences, skills, and abilities. will be provided. Thus, since human capital is mainly in the minds of individuals, this vital and important knowledge is provided to the organizations when employees are willing to cooperate and share knowledge. In addition, effective arrangements and mechanisms provided by organizations play a critical role as well. The successful advancement 
of knowledge management requires employees to share what they know in the organization with others. Knowledge sharing is thus considered as the most basic function of knowledge management in the organization. On the other hand, knowledge sharing in organizations has had positive consequences and led to the improvement of organizational indicators.

By knowledge sharing, new ideas and opportunities arise via the socialization and transformation of individuals into knowledge workers. The culture of knowledge sharing is based on trust. In other words, trust is essential for informing, involving, and motivating organizational individuals during organizational change. Knowledge sharing culture is a culture in which knowledge sharing is the norm, not the exception, and individuals are rewarded for working together, collaborating, and sharing knowledge. (Biranvand et al., 2017) considers knowledge sharing as the exchange of knowledge among individuals, i.e. those who transmit knowledge and those who absorb it. He also believes that knowledge sharing focuses on human capital and interaction among individuals. From an academic point of view, knowledge sharing is known as awareness of knowledge-related needs and making knowledge available to others by creating technical and systematic infrastructures. This means that knowledge can be shared through technology as well as through a systematic strategy within an organization. One of the main goals of the application of knowledge management and knowledge sharing strategy in educational institutions is to increase the quality and effectiveness of learning processes, as well as to develop curricula and research.

(Namvar et al., 2018) have divided the knowledge sharing process into two main components: (1) Knowledge donation: the transfer of one person's intellectual capital by himself to another person, and (2) Knowledge collection: Individuals actively refer to their colleagues to learn what they know.

\section{Materials and Methods}

Since this study intends to study the effective factors in the knowledge sharing model among education staff and therefore by presenting new solutions that are faced in the continuation of the research process, which is to identify the effective factors in the knowledge sharing model. Therefore, the researcher has given examples of typology and typology of sharing model by bringing several examples. Considering that the method of this research is descriptive-analytical and we know that the most important and basic research method in the analytical approach is the library technique. Therefore, the research method of this article is library. However, in addition to the library method, the Internet resources, existing software, articles and lectures of professors in this field and CDs will be used.

\section{Results}

\section{Factors affecting knowledge sharing}

Active knowledge sharing occurs among employees when individuals voluntarily transfer their knowledge and also gather the knowledge they need from others out of passion and motivation, which is itself a factor in creating a knowledge sharing cycle in the organization. In this cycle, only a person gives his knowledge to others through motivation and voluntarily and honestly, and also through motivation, he will receive the required knowledge from others correctly (Biranvand et al., 2017).

The ultimate goal of employee knowledge sharing is to strive to transfer and transform the experience and knowledge of all individuals into organizational assets and resources, to increase efficiency and better advance organizational affairs. (Khayat Moghadam et al., 2017) noted that if we want individuals in an organization to share what they learn, conditions must be provided in the organization, where knowledge sharing is an individual advantage. By reviewing the factors 
affecting knowledge sharing in recent studies, they can be classified into four categories: individual, organizational, information technology and social factors.

1. Individual factors affecting knowledge sharing

Individual factors of knowledge sharing include those factors that encourage or deter a person from sharing their knowledge assets with others. The most important of these factors include the following.

Trust: Interpersonal trust or trust among colleagues, which is an important feature of organizational culture, has a profound effect on the knowledge sharing process. (Biranvand et al., 2017) also stated in a study that trust in the organizational environment reduces the fear of losing unique value in individuals because this fear can have a negative effect on the success process of knowledge sharing, that is, whenever employees fear If they do not lose their experience or their position, they will share personal experiences better and more.

Personality and personal characteristics: Personal characteristics are factors that affect the sharing of knowledge among individuals in the organization. For example, individuals who are extrovert with high self-confidence tend to share knowledge and experiences, compared to introvert individuals. Findings of a study by world (Khayat Moghadam et al., 2017) showed that altruism has an effect on individuals' attitudes toward knowledge sharing, while reputation is not a significant explanatory factor affecting individuals' attitudes toward knowledge sharing. Enjoying Knowledge Sharing: (Akhavan \& Hosseini, 2016) believe that the enjoyment of helping others and sharing knowledge in group interactions with others enhances knowledge sharing behavior in the organization. (Davenport \& Prosak, 1998) in his research pointed to a positive and significant relationship between the pleasure of helping others and knowledge sharing.

Motivation: My (Ali Purdarvishi, 2012) believes that motivation independently has a significant effect on knowledge sharing in organizations. He states in his research that there is no significant relationship between controlled motivation and knowledge sharing. Elsewhere, (Kashani \& Nikokar Hani, 2014) showed that external stimuli will increase the tendency to share knowledge in the individual.

Self-efficacy: (Namvar et al., 2018) detected a strong relationship between self-efficacy in the future and the degree to which an individual is willing to share knowledge. (Davenport \& Prosak, 1998) in an exploratory study in a multinational corporation showed that there was a strong and significant relationship between self-efficacy and self-expression of knowledge exchange behavior.

2. Organizational factors affecting knowledge sharing

According to (Biranvand et al., 2017), the organizational dimension of knowledge sharing includes a set of organizational characteristics that affect the quality of knowledge sharing among the employees of that organization or between an organization and other organizations. Undoubtedly, one of the key and important factors in knowledge management is the ability of organizations to share knowledge. In this section, some organizational factors affecting knowledge sharing are examined.

Organizational Rewards: If reward is focused on collective performance, it is likely to encourage knowledge sharing in groups | And facilitates the acceptance of ideas for innovation, this will lead to voluntary behaviors among employees. In this regard, (Akhavan et al., 2017) showed that the reward system has positive and significant effects on knowledge sharing.

(Khayat Moghadam et al., 2017), stated that organizations are sometimes motivated by using external incentives such as financial incentives, performance-related salaries or rewards, job promotions, promotions, training opportunities, job security, or any combination of incentives. In this case, their employees contribute to their knowledge sharing.

Organizational culture: Organizational culture is one of the key aspects in sharing knowledge and finding the right type of culture and its key indicators. One of the key issues in knowledge sharing is its implementation. The impact of culture on knowledge sharing is a recurring theme in recent research. (Mehdian Rad et al., 2018) found that organizational culture was the most important factor in increasing knowledge sharing in transnational projects. (Namvar et al., 2018) acknowledged a positive and significant relationship between organizational culture and knowledge sharing. (Akhavan \& Hosseini, 2016) also emphasized in their research that the 
entrepreneurial culture in the organization had an effect on the better implementation of knowledge sharing. In addition, they introduced three entrepreneurial cultures, goal achievement, and slow movement.

Two important dimensions of formalization and focus on organizational structure are effective in knowledge sharing, so that if the organizational structure engages in individualistic behaviors and individuals are rewarded for storing and maintaining knowledge, then the amount and speed of knowledge sharing in the organizations would be highly decreased (Akhavan \& Hosseini, 2016). Leadership: (Akhavan et al., 2017) recognized in a study that empowerment of leadership is effective in the success rate of knowledge sharing. study also revealed a positive and significant relationship between support for top management and knowledge sharing.

3. Social factors affecting knowledge sharing

Social factors: (Khayat Moghadam et al., 2017) has conducted many studies in the field of knowledge management and knowledge sharing; however, these studies have a limited empirical basis and at most can be described as exploratory studies. His findings indicate that human and social factors are highly influential in knowledge sharing. This section provides a brief overview of the social factors discussed in the literature.

Cyberspace: (Ali Purdarvishi, 2012) in a study examined the social factors influencing the phenomenon of knowledge sharing. In his research, he presented a theoretical framework based on the three factors of virtual networks, social capital and social trust. Using model analysis through causal relationships, it was found that cyberspace can be considered as one of the important factors in the success of the knowledge sharing chain as a tool for knowledge search and sharing. In his research, he failed to show the positive effect of social trust on the success of knowledge sharing.

Social Capital: The (Akhavan \& Hosseini, 2016) in a study examined the factors that affect knowledge sharing in virtual organizations. They found that social capital positively affects employees' perceptions and their behaviors in knowledge sharing. The multiple effects of the nature of social capital on knowledge transfer were studied by (Khayat Moghadam et al., 2017). In this study, it is suggested that host network situations such as distance and structural change have a significant effect on their knowledge transfer.

4. IT factors

In knowledge management, technology is of particular importance. Although technology is not considered as the heart of knowledge management, but as a useful tool, it plays a vital role in increasing the level of knowledge sharing among employees. According to McDead Mott, the current trend in information technology development encourages organizations to think about new ways of sharing knowledge, such as storing knowledge-based documents and using electronic networks.

\section{Discussion}

Various studies have examined the role of information and communication technology in knowledge sharing. (Namvar et al., 2018) pointed to the role of information and communication technology as one of the powerful factors in knowledge management. The existence of appropriate technology infrastructure will have a highly positive impact on the process of knowledge sharing in organizations and communities, which will facilitate this process.

The nature of organizational knowledge: Organizations have two types of knowledge, known as explicit and implicit knowledge. "(Ali Purdarvishi, 2012) first distinguished between explicit and implicit knowledge. According to Polani, it is difficult to express tacit knowledge in words, the mental and sensory nature of tacit knowledge makes it highly difficult to process and transfer the acquired knowledge in logical and structured ways. Explicitly constitute the organization. Explicit knowledge is typically both well-documented and accessible. Explicit knowledge can be easily processed by computer, electronic transmission and storage in databases; Organizations need to integrate both types of knowledge. In order for tacit knowledge to be shared 
in the organization, it must become explicit knowledge so that it can be understood by everyone. In fact, when this process occurs, the organization produces knowledge. The transfer and exchange of explicit and implicit knowledge among individuals and organizational groups takes place in four ways: (1) Transformation of tacit knowledge into new tacit knowledge or socialization, (2) Transformation of tacit knowledge into explicit knowledge or externalization, (3) Transformation of explicit knowledge into new and more complex explicit knowledge by integration, and (4) Transformation of explicit knowledge into tacit knowledge or internalization (Sinaei et al., 2017).

Noteworthy, designing and testing the knowledge sharing model among educational administrative staff to discover how knowledge and experiences interact and are shared would lead to better, faster, and more effective learning, increase creativity, and improve individual and organizational performance of employees.

\section{Conclusion}

According to the research findings, it can be concluded that the four dimensions of the knowledge sharing model among educational staff are well-fitted. Accordingly, it can be mentioned that knowledge sharing saves costs due to the loss of intellectual capital by leaving employees for any reason in an organization, reducing costs due to non-repetition of repetitive works, making adaptation to change, and ensuring the dissemination of best practices. The organization enables them to solve their problems and issues, so knowledge sharing is fully accepted as a necessity in today's organizations. In this regard, organizations provide a set of solutions in various individual and organizational areas for all management processes and knowledge sharing and implement technology (environmental) and trans-environmental measures.

\section{References}

Namvar M. \& Razavi M. \& Kalateh Seifri M. (2018), The effect of intellectual capital on productivity with emphasis on knowledge sharing in experts of sports and youth departments of Khorasan Razavi province, Journal of Organizational Behavior Management Studies in Sport, 5(1): 25-32.

Mehdian Rad A. \& Alvani M. \& Fazli S. (2018), Designing a knowledge sharing model in the Tax Affairs Organization and its role in promoting organizational effectiveness and popularity, Journal of Taxation, 26(38): 159-168.

Khayat Moghadam S. \& Taheri Lari M. \& Aliaei L. (2017), Factors affecting knowledge sharing in the supply chain (Case study: Khorasan electricity supply chain), General management in management, 4(8): 83-93.

Akhavan P. \& Hosseini S. (2016), Investigation of motivational and organizational factors affecting the formation of knowledge sharing behavior among employees: A case study in an industrial research and development center, Journal of Information Processing and Management, 30(1):1051-1084.

Davenport F. \& Prosak E. (1998), Investigating the effect of job attitude on knowledge sharing and its relationship with organizational citizenship behavior in Ghavamin Bank, Quarterly Journal of Development and Transformation Management, 14(2): 1-10.

Ali Purdarvishi Z. (2012), Presenting a Model of Factors Affecting the Knowledge Sharing of Departments of Islamic Azad University (Survey of North Tehran Branch and Science and Research) Information Technology Management, 10(4): 91-116.

Kashani R. \& Nikokar Hani H. (2014), Knowledge sharing, Investigating the role of factors affecting it and productivity of the organization, Productivity management (beyond management), 31(8), 51-73.

Akhavan P. \& Heidari J. \& Zahedi M. (2017), Knowledge Management: Employee Technical Knowledge Extraction (with Operational Approach), Malek Ashtar University of Technology Press, Tehran: First Edition Esmaeil pour, 16(1), 233-240. 
Sinaei H. \& Frisat H. \& Nadaf M. (2017), Investigating the effective factors on knowledge sharing and its impact on individual performance in the financial and banking industry, Journal of Executive Management, 9(18): 143-168.

Biranvand A. \& Shabani A. \& Mohammadi Provincial M. (2017), Investigating the Factors Affecting Librarians' Knowledge Sharing and Presenting a Model for Predicting Their Behavior (Case Study: Fars Province Public Libraries). Library and Information Science Studies, 24(19): 39-60. 